\title{
Corrigendum: Transient Heat Transfer Characteristics of Twisted Structure Heated by Exponential Heat Flux
}

\author{
Li Wang ${ }^{1 *}$ and Qiusheng Liu ${ }^{2}$ \\ ${ }^{1}$ School of Mechanical Engineering, Nantong University, Nantong, China, ${ }^{2}$ Department of Marine Engineering, Kobe University, \\ Kobe, Japan
}

Keywords: exponential heat flux, twisted plate, transient heat transfer, forced convection, heat transfer enhancement

\section{A Corrigendum on}

Transient Heat Transfer Characteristics of Twisted Structure Heated by Exponential Heat Flux by Wang, L. (2021). Front. Energy Res. 9:771900. doi: 10.3389/fenrg.2021.771900

The author Qiusheng Liu was not initially included as an author in the published article despite their contribution. The corrected Author Contributions statement appears below.

\section{AUTHOR CONTRIBUTIONS}

LW contributed to the conception of the study, collected the experiment data, performed the analysis, and wrote the manuscript. QL has contributed to experimental apparatus and paper instructions.

\section{OPEN ACCESS}

Edited and reviewed by: Xuewen Cao,

China University of Petroleum (East

China), China

*Correspondence:

Li Wang

wang1988@ntu.edu.cn

Specialty section:

This article was submitted to Advanced Clean Fuel Technologies,

a section of the journal

Frontiers in Energy Research

Received: 20 December 2021 Accepted: 13 January 2022

Published: 08 February 2022

Citation:

Wang L and Liu Q (2022)

Corrigendum: Transient Heat Transfer

Characteristics of Twisted Structure

Heated by Exponential Heat Flux.

Front. Energy Res. 10:839701.

doi: 10.3389/fenrg.2022.839701
Further, in the original article, we neglected to include an acknowledgement. The updated Acknowledgments statement appears below.

\section{ACKNOWLEDGMENTS}

The experiment work in this paper was done in Graduate School of Marine Engineering, Kobe University, Japan. We would like to thank for the support by the Japan Society for the Promotion of Science (JSPS) (Grant-in Aid for Scientific Research (C), KAKENHI, No. 15K05829).

In the original article Figure 1, Figure 2, and Figure 3 were not cited in the article. The citation has now been inserted in section 2 'EXPERIMENTAL STUDY', sub-section 2.1 'Experimental Apparatus', and should read:

"The experimental apparatus consisted of gas cylinder (1), compressor (2), surge tanks (3) (9), preheater (6), cooler (8), vacuum pump (10), and the test section (7), as shown in Figure 1 (Liu et al., 2014)."

"The test heater was mounted horizontally along the center axis of the circular test channel, which is made of stainless steel with inside diameter of $20 \mathrm{~mm}$, as shown in Figure 2 (Liu et al. 2014). A twisted tape with five pitches (each was $180^{\circ}$ twisted with $20 \mathrm{~mm}$ in length) was used in the experiment."

"A high-speed analog computer was applied in part 2 to support a rapid and precise calculationfeedback process for the heat generation and heater temperature control. While the signal input and output data processing were fulfilled with a personal computer (PC) (Figure 3) (Liu et al., 2014)."

The authors apologize for these errors and state that this does not change the scientific conclusions of the article in any way. The original article has been updated. 


\section{REFERENCES}

Liu, Q., Zhao, Z., and Fukuda, K. (2014). Transient Heat Transfer for Forced Flow of Helium Gas along a Horizontal Plate with Different Widths. Int. J. Heat Mass Transfer 75, 433-441. doi:10.1016/j.ijheatmasstransfer.2014. 03.077

Publisher's Note: All claims expressed in this article are solely those of the authors and do not necessarily represent those of their affiliated organizations, or those of the publisher, the editors and the reviewers. Any product that may be evaluated in this article, or claim that may be made by its manufacturer, is not guaranteed or endorsed by the publisher.

Copyright $\odot 2022$ Wang and Liu. This is an open-access article distributed under the terms of the Creative Commons Attribution License (CC BY). The use, distribution or reproduction in other forums is permitted, provided the original author(s) and the copyright owner(s) are credited and that the original publication in this journal is cited, in accordance with accepted academic practice. No use, distribution or reproduction is permitted which does not comply with these terms. 